Article

\title{
Effects of Gamma-Valerolactone Assisted Fractionation of Ball-Milled Pine Wood on Lignin Extraction and Its Characterization as Well as Its Corresponding Cellulose Digestion
}

\author{
Muhammad Ajaz Ahmed ${ }^{1}$, Jae Hoon Lee ${ }^{2}$, Arsalan A. Raja ${ }^{3}$ and Joon Weon Choi ${ }^{1, *}$ \\ 1 Institute of Green-Bio Science and Technology, Seoul National University, Pyeongchang 232-916, Korea; \\ m.ajaz@snu.ac.kr \\ 2 Department of Forest Sciences, Seoul National University, Seoul 151-921, Korea; tirchonail@snu.ac.kr \\ 3 Department of Chemical Engineering, University of Hafr Al-Batin, Hafr Al-Batin 31991, Saudi Arabia; \\ arsalanr@uohb.edu.sa \\ * Correspondence: cjw@snu.ac.kr
}

Received: 31 January 2020; Accepted: 25 February 2020; Published: 28 February 2020

check for updates

\begin{abstract}
Gamma-valerolactone (GVL) was found to be an effective, sustainable alternative in the lignocellulose defragmentation for carbohydrate isolation and, more specifically, for lignin dissolution. In this study, it was adapted as a green pretreatment reagent for milled pinewood biomass. The pretreatment evaluation was performed for temperature $\left(140-180^{\circ} \mathrm{C}\right)$ and reaction time $(2-4 \mathrm{~h})$ using $80 \%$ aqueous GVL to obtain the highest enzymatic digestibility of $92 \%$ and highest lignin yield of $33 \%$. Moreover, the results revealed a positive correlation $\left(R^{2}=0.82\right)$ between the lignin removal rate and the crystallinity index of the treated biomass. Moreover, under the aforementioned conditions, lignin with varying molecular weights (150-300) was obtained by derivatization followed by reductive cleavage (DFRC). 2D heteronuclear single quantum coherence nuclear magnetic resonance (2D-HSQC-NMR) spectrum analysis and gel permeation chromatography (GPC) also revealed versatile lignin properties with relatively high $\beta-\mathrm{O}-4$ linkages $(23.8 \%-31.1 \%)$ as well as average molecular weights of 2847-4164 with a corresponding polydispersity of 2.54-2.96, indicating this lignin to be a heterogeneous feedstock for value-added applications of biomass. All this suggested that this gamma-valerolactone based pretreatment method, which is distinctively advantageous in terms of its effectiveness and sustainability, can indeed be a competitive option for lignocellulosic biorefineries.
\end{abstract}

Keywords: pinewood; green pretreatment; enzymatic hydrolysis; lignin structural features

\section{Introduction}

In the context of the non-sustainable supply of fossil fuels, lignocelluloses have emerged as one potentially suitable option to theoretically swamp the existing petroleum-based fuels [1]. These lignocellulosic substrates are highly likely to shape the future of the bioeconomy given their sustainable supply, relative abundance and readily collectible nature [2]. These biomasses, in their typical native conformation, are composed of sugar polymers of glucose and xylose and are surrounded by a protective sheath of lignin [3]. This renewable feedstock is a rich source for the production of fuels, commodity chemicals and even biomaterials [4]. However, in their native form, certain features associated with their structural integrity make them unresponsive to any external attacks [5]. For example, the complexity of the cell wall structure, degree of polymerization, cellulose crystallinity, extent of lignification and compositional heterogeneity even within one species of biomass, etc. [6,7] are such major factors. Therefore, pretreatment, to make biomass available for subsequent processing, has been envisaged as 
an unavoidable step in biomass refining processes [8]. This fractionation step, in principle, disrupts the biomass native structure, exposes the sugar polymers for the subsequent enzymatic process and makes lignin available for easy extraction [9]. There have been a fair deal of studies involving a variety of pretreatment strategies including acids, alkaline reagents, hydrothermal pretreatment, organosolv pretreatment, ionic liquids, steam explosion and even biological pretreatments [10]. These pretreatments have their pros and cons [11]. For example, acidic pretreatments, along with steam explosion and hydrothermal ones, dissolve mostly the xylose portion and keep lignin within a biomass web [12]. On the other hand, ionic liquids also have significant effects on biomass fractionation, but their burdensome cost prohibits their commercial-scale applications [13]. Moreover, biological treatments are associated with prolonged processing times, making them unfavorable for biorefining processes [14]. Organosolv treatments, as compared with other pretreatment schemes, cause considerable alterations in the structural features of biomass [15]. These treatments disrupt the biomass by creating internal slits for enhanced bioconversion efficiency. Moreover, from these solvent pulping strategies, lignin can be recovered with significant characteristic features [16]. This isolated lignin, with adequate purity having low polysaccharides, is highly desired for making lignin-based compounds with tailored properties. Recently, gamma-valerolactone (GVL) has emerged as one such sustainable green solvent for biomass fractionation [17]. This organic solvent is a self-sustained non-toxic product formed within a lignocellulosic biorefinery and is capable enough to extract lignin at near-neutral solvent conditions [18]. Typically, GVL/acid/water has been mostly applied for an enhanced delignification rate with improved cellulose digestion [19]. As it is miscible with water, it induces better hydrolytic effects for biomass to dissolve out the lignin portion [20]. This reagent has also been applied with synergetic effects of metal salts, microwaves and acids [21,22]. Therefore, in this study, we adapted a GVL assisted fractionation of pinewood biomass to study its effects on the lignin isolation and its characteristic features along with the enzymatic digestion of corresponding carbohydrate fractions. Formally, $80 \%$ aqueous GVL was employed along with ball-milled pinewood into stainless steel reactors and was treated for time intervals of $2-4 \mathrm{~h}$ with a temperature range of $140-180^{\circ} \mathrm{C}$.

\section{Materials and Methods}

\subsection{Preparation of Biomass}

Pinewood biomass was chosen as a model substrate in this study. It was collected from Gangwon Province, South Korea. Prior to being employed for experimentation, it was air-dried, chopped and finally ground to a particle size of 60 mesh. It was subsequently methanol extracted for $24 \mathrm{~h}$ and was then air-dried at a temperature of $60^{\circ} \mathrm{C}$. The compositional analysis of this methanol extracted biomass was determined according to two-step acid hydrolysis of the National Renewable Energy Laboratory's (NREL) standard analytical procedure. Its composition was revealed to be: glucan $44 \%$, xylan $7 \%$, mannan $13 \%$, Klason lignin $28 \%$ and $4 \%$ moisture contents. All the chemicals used in this study were of analytical grade and were employed in experimentation without any further modification.

\subsection{GVL Assisted Fractionation of the Biomass}

The pinewood biomass was subjected to milling for $20 \mathrm{~h}$ (on the basis of initial laboratory trials data not shown) using a laboratory ball mill prior to being used in the pretreatment experiments. Later on, lab-scale specially designed stainless-steel reactors, with a working volume of $300 \mathrm{~mL}$, were used in the pretreatment experiments. The milled pinewood was loaded into the reactors at a solids loading of $5 \%$ (20:1 liquid to solid ratio). A measured amount of gamma-valerolactone was added, and the slurry was mixed well to near complete homogenization prior to heating on an oil bath. For all the experiments, a $\mathrm{pH}$ value of 6-7 was already present, and no external addition of any acidic reagent was made during the designated pretreatment heating time. After fractionation, the reactors were quenched on an ice bath to cool down to room temperature. Afterward, the biomass slurry was subjected to filtration with a Buchner funnel and vacuum pump assembly to collect the solid residue and the dissolved lignin 
fractions as filtrate. The liquid fractions were subjected to lignin separation via the water precipitation method. For this, a specified volume of DI water (4 times the experimental volume) was added to all the recovered liquid fractions and was left overnight. It was then separated by centrifugation, freeze-dried and saved in the refrigerator for any further experiments. The lignin yield was calculated on the basis of the initial lignin contents of the raw biomass on a weight basis. The corresponding filtered solid residue was washed and dried in an oven overnight for subsequent processing.

\subsection{Enzymatic Saccharification}

For enzymatic hydrolysis, GVL treated oven-dried biomass was loaded into Erlenmeyer flasks at $5 \%$ solid loading with $50 \mathrm{mM}$ sodium citrate and citric acid buffer solution according to one of our previous studies [23]. The enzymatic blend of Cellic C-Tec 2 (Novozymes, Denmark), derived from Trichoderma reesei, with a dose of $30 \mathrm{FPU} / \mathrm{g}$ of biomass was used. This enzymatic saccharification was performed at $50^{\circ} \mathrm{C}$ and $200 \mathrm{rpm}$ for $72 \mathrm{~h}$ in a shaking incubator, and the samples were taken periodically.

\subsection{Compositional Analysis and Biosugar Quantification}

To determine the biomass composition, a two-step acid hydrolysis protocol adapted from the National Renewable Energy Laboratory (NREL) was employed [24]. Briefly, dried treated biomass was first subjected to $72 \%(\mathrm{v} / \mathrm{v}) \mathrm{H}_{2} \mathrm{SO}_{4}$ hydrolysis at room temperature, then the second hydrolysis was done with autoclaving at $121^{\circ} \mathrm{C}$ for $1 \mathrm{~h}$. After cooling at room temperature, the liquid was filtered out and prepared for HPLC analysis, whereas the solid residue was dried overnight for lignin quantification. The monomeric sugar fractions were quantified by HPLC equipped with an RID detector (Thermoscientific Ultimate 3000) and a Carbosep CHO-87 P column (Concise Solutions, USA). The column temperature was set at $65^{\circ} \mathrm{C}$, and DI water was used as a mobile phase with a flow rate of $0.6 \mathrm{~mL} / \mathrm{min}$.

\subsection{Statistical Analysis}

We used regression analysis to interpret the correlation of enzymatic digestibility and XRD with lignin yield. The stated $R^{2}$ values have been reported on the basis of linear regression to clarify the explanatory roles of enzymatic digestibility and XRD on the lignin yield, respectively. This analysis was performed with the help of SigmaPlot version 10.0.

\subsection{Characterization of Isolated Lignin and Fractionated Biomass}

The recovered lignin fractions were analyzed by gel permeation chromatography (GPC), derivatization followed by reductive cleavage (DFRC) and 2D heteronuclear single quantum coherence nuclear magnetic resonance (2D-HSQC-NMR) spectrum according to our previous study [25]. To determine the weight average $(\mathrm{Mw})$ and number average $(\mathrm{Mn})$ molecular weights, each isolated fraction was first subjected to acetylation in pyridine/acetic anhydride (1:1) solution and was periodically shaken after being maintained at a temperature of $105^{\circ} \mathrm{C}$ for $2 \mathrm{~h}$. After this, almost $20 \mathrm{mg}$ of this acetylated lignin was dissolved in $2 \mathrm{~mL}$ of tetrahydrofuran and then analyzed using a GPC, Agilent 1200, USA (equipped with an ultraviolet detector (UV) on a PL-gel $5 \mathrm{~mm}$ Mixed-c. column, calibrated with polystyrene standards), and THF was used as a mobile phase while it was flowed at a rate of $1 \mathrm{~mL} / \mathrm{min}$. For DFRC analysis, a previous classical approach was adapted in which the extracted lignin samples, $20 \mathrm{mg}$ for each sample, were dissolved in $4 \mathrm{~mL}$ AcOH and $1 \mathrm{~mL} \mathrm{AcBr}$ solution and kept at $50{ }^{\circ} \mathrm{C}$ for $1 \mathrm{~h}$ with rigorous periodic shaking. Afterward, the residue was obtained by evaporating the mixture on a rotary evaporator. To this residue, $2 \mathrm{~mL}$ of dioxane/acetic acid/water (5:4:1, v/v/v) was added, and subsequently, zinc dust $(50 \mathrm{mg}$ ) was also added with stirring and then the whole solution was kept for $1 \mathrm{~h}$ at room temperature. Later on, after the intended time, a precise amount of the internal standard tetracosane was added into the solution, which was extracted by the mixture with $\mathrm{CH}_{2} \mathrm{Cl}_{2}$ and saturated $\mathrm{NH}_{4} \mathrm{Cl}$. After this, the $\mathrm{pH}$ of the aqueous phase was dropped down to 3 by adding $3 \%$ $\mathrm{HCl}$, and then finally, the organic layer was separated. The water phase was extracted twice with $\mathrm{CH}_{2} \mathrm{Cl}_{2}$, and the combined $\mathrm{CH}_{2} \mathrm{Cl}_{2}$ fractions were dried over $\mathrm{MgSO}_{4}$, and ultimately, the filtrate was 
evaporated under reduced pressure. The residue was then subjected to acetylation employing $0.5 \mathrm{~mL}$ each of acetic anhydride and pyridine for at least $1 \mathrm{~h}$ with periodic shaking. All the residual matter was then filtered using syringe filters and finally subjected to quantification by GC-MS (Agilent 7890B USA). For 2D-HSQC-NMR, the lignin samples were prepared using $20 \mathrm{mg}$ of lignin dissolved in $0.75 \mathrm{~mL}$ DMSO-D6, and then the analysis data were acquired with a Bruker AVANCE 600 spectrometer (Bruker, Germany). Raw and pretreated pinewood samples were characterized in terms of their crystallinity indices as well. For this, the crystallinity index $(\mathrm{CrI})$ was determined by measuring $\mathrm{X}$-ray diffraction (XRD) using a powder X-ray diffractometer (Bruker, D8 Advance with DAVINCI Germany). A sample was scanned at a rate of $2^{\circ} / \mathrm{min}$ in the $2 \theta$ range of $3^{\circ}-60^{\circ}$, and the CrI was estimated according to Equation (1).

$$
\operatorname{CrI}(\%)=\left[\left(\mathrm{I}_{\text {Crystalline }}-\mathrm{I}_{\text {Amorphous }}\right) / \mathrm{I}_{\text {Crystalline }}\right] \times 100 \%
$$

where $\mathrm{I}_{\text {crystalline }}=$ intensity at $22.26^{\circ}$ and $\mathrm{I}_{\text {amorphous }}=$ intensity at $15.72^{\circ}$.

\section{Results and Discussion}

\subsection{Effects of Pretreatment Severity on the Chemical Composition of Biomass}

Temperature, in general, is a critical parameter in chemical reactions, and this is also the case for lignocellulosic biomass pretreatment. To observe the effects of GVL fractionation under different thermal conditions on the milled pinewood composition, a reaction was conducted for $2-4 \mathrm{~h}$ in the presence of $80 \%$ aqueous GVL with temperature varying from $120^{\circ} \mathrm{C}$ to $160^{\circ} \mathrm{C}$.

The chemical composition of the treated biomass along with solid recovery are listed in Table 1. The solid residue, left after the GVL treatment, ranged from $86 \%$ to $50 \%$, mainly exhibiting a counter-wise behavior to the treatment severity. This high biomass dissolution has already been found in a similar GVL assisted fractionation of biomass [26].

Table 1. Effects of pretreatment conditions on the chemical composition of pinewood biomass.

\begin{tabular}{|c|c|c|c|c|c|c|c|c|}
\hline \multirow{2}{*}{ Sample } & \multicolumn{2}{|c|}{ GVL Extraction Conditions } & \multirow{2}{*}{$\begin{array}{c}\text { Solid } \\
\text { Recovery } \\
(\%)\end{array}$} & \multicolumn{4}{|c|}{ Solid Composition (\%) } & \multirow{2}{*}{$\begin{array}{l}\text { Solution pH } \\
\text { after Complete } \\
\text { Reaction }\end{array}$} \\
\hline & Time (hours) & Temperature $\left({ }^{\circ} \mathrm{C}\right)$ & & Glucan & Xylan & Mannan & Lignin & \\
\hline \multirow{6}{*}{ Pinewood } & 2 & 140 & 86 & 42 & 5 & 14 & 29 & 6.0 \\
\hline & 4 & 140 & 80 & 38 & 6 & 12 & 30 & 5.9 \\
\hline & 2 & 160 & 70 & 37 & 4 & 15 & 26 & 5.5 \\
\hline & 4 & 160 & 65 & 34 & 10 & 12 & 25 & 5.2 \\
\hline & 2 & 180 & 60 & 28 & 9 & 10 & 24 & 4.0 \\
\hline & 4 & 180 & 50 & 25 & 8 & 12 & 30 & 3.0 \\
\hline
\end{tabular}

The biosugars, glucan and mannan, were mainly not altered due to this severity showing only a scant variation in their composition. Xylan, however, was dissolved a bit more than the glucan and mannan. This xylan composition, as a typical amorphous regions dissolution trend, was also supported by the low $\mathrm{pH}$ value that was a direct function of the treatment severity. This $\mathrm{pH}$ variation ranged from 6 at 140:2 h to 3 at the harshest conditions of $180^{\circ} \mathrm{C}$ for a treatment operation of $4 \mathrm{~h}$. The glucan and mannan were also affected at a high $\mathrm{pH}$ and high thermal environment, indicating that GVL was also effective in dissolving the cellulose portion, although only partly. This biosugar recovery, despite the harsh processing conditions, was quite high. For example, it was substantially higher than a previous Fenton-based study in which almost half of the glucan was lost [27].

\subsection{Lignin Extraction from Ball-Milled Pinewood}

In order to find out the effects of treatment conditions on the lignin yield, the lignin extraction efficiency, based on initial raw lignin contents, was also determined and is shown in Table 2. Briefly, the filtrate obtained from all of the six performed experiments under our described conditions was first 
added to $800 \mathrm{~mL}$ of DI water and left overnight to settle down the lignin as precipitates. Afterward, these fractions were centrifuged using a laboratory centrifuge machine. The supernatant was decanted off carefully, and the leftover solid fractions were subjected to freeze-drying for $24 \mathrm{~h}$. These freeze-dried lignin samples were used for their characterization and further analysis. The lignin yield, in a somewhat expected manner, showed a gradual trend in comparison with the treatment severity. For example, starting from less harsh treatment conditions of 140:2, it was quite a low yield, with only $3.0 \%$ lignin. However, as the thermal severity was increased over a long retention time, the yield was correspondingly increased to 33\%. This trend showed that the ball-milled biomass was dissolved in GVL and it was likely to separate out the acetyl contents to create an acidic environment as the treatment severity was prolonged. The highest lignin yield of 33\% was obtained at 180:4, the extreme conditions in our case. Interestingly, the biomass solid recovery and the corresponding $\mathrm{pH}$ value of the final solution was around $50 \%$ and 3, respectively. This shows that there was indeed some acidic environment due to harsher treatment conditions.

Table 2. Lignin yield and corresponding glucose release from treated biomass.

\begin{tabular}{|c|c|c|c|}
\hline \multirow{2}{*}{ Sample } & \multicolumn{2}{|c|}{ GVL Extraction Conditions } & \multirow{2}{*}{ Lignin Yield (\%) } \\
\hline & Time (hours) & Temperature $\left({ }^{\circ} \mathrm{C}\right)$ & \\
\hline \multirow{6}{*}{ Pinewood } & 2 & 140 & 3.0 \\
\hline & 4 & 140 & 6.5 \\
\hline & 2 & 160 & 18 \\
\hline & 4 & 160 & 27 \\
\hline & 2 & 180 & 29 \\
\hline & 4 & 180 & 33 \\
\hline
\end{tabular}

\subsection{Enzymatic Hydrolysis of Solid Fractions}

In order to observe the GVL assisted treatment efficacy, the cellulose digestion of the treated solid residues as well as the untreated ones was performed, and the results are delineated in Figure 1. As expected, the untreated biomass showed a very low enzymatic saccharification yield of nearly $25 \%$, mainly due to its intact and smooth surface providing less effective enzymatic absorption sites. However, for the treated biomass fractions, the glucose release and the corresponding enzymatic digestibility rose in a gradual way, exhibiting that treatment severity had a positive impact on glucose release. Initially, the yield was not that high (almost $60 \%$ for $140-160^{\circ} \mathrm{C}$ ); however, it increased in a dramatic fashion $(92 \%)$ when the thermal conditions went beyond $160^{\circ} \mathrm{C}$ viz $\left(180^{\circ} \mathrm{C}: 4 \mathrm{~h}\right)$. The lignin was also removed when the treatment conditions were prolonged, so it can be anticipated that, in our case, the biomass web deconstruction, along with the removal of lignin, provided enhanced accessibility for enzymatic penetration. From here, it can be anticipated that the cellulose digestion was drastically improved for the ball-milled pinewood biomass with GVL pretreatment. This treatment operation, due to its biomass dissolution properties, disrupted the biomass native matrix and exposed inner surfaces, which escalated the subsequent enzymatic saccharification. From here, it can be conclusively suggested that this treatment can be one suitable option for lignocellulosic ethanol production.

\subsection{Correlation of Enzymatic Hydrolysis with Delignification and Crystallinity Index}

Since there was a significant lignin removal during the GVL treatment process, we also determined the crystallinity index of the treated and the untreated biomass samples to observe any correlation with enzymatic digestibility. As shown in Figure 2, both the crystallinity indices along with the delignification showed a positive correlation with the enzymatic digestibility. The high value of $R^{2}$ also proves this good agreement. From here, it can be easily concluded that the governing factor for heightened enzymatic hydrolysis in our case is both the lignin removal as well as the crystallinity index. A similar trend was 
also observed in a previous study where they found an $\mathrm{R}^{2}=0.72$ for lignin removal and enzymatic hydrolysis [28]. Interestingly, a previous study found a negative correlation of crystallinity with the enzymatic digestibility [19], but in our study, a contrary result was found, which shows that the governing factor for enhanced glucose yield, at least in our case, is both the crystallinity index and the lignin removal.

Enzymatic Digestibility VS Time

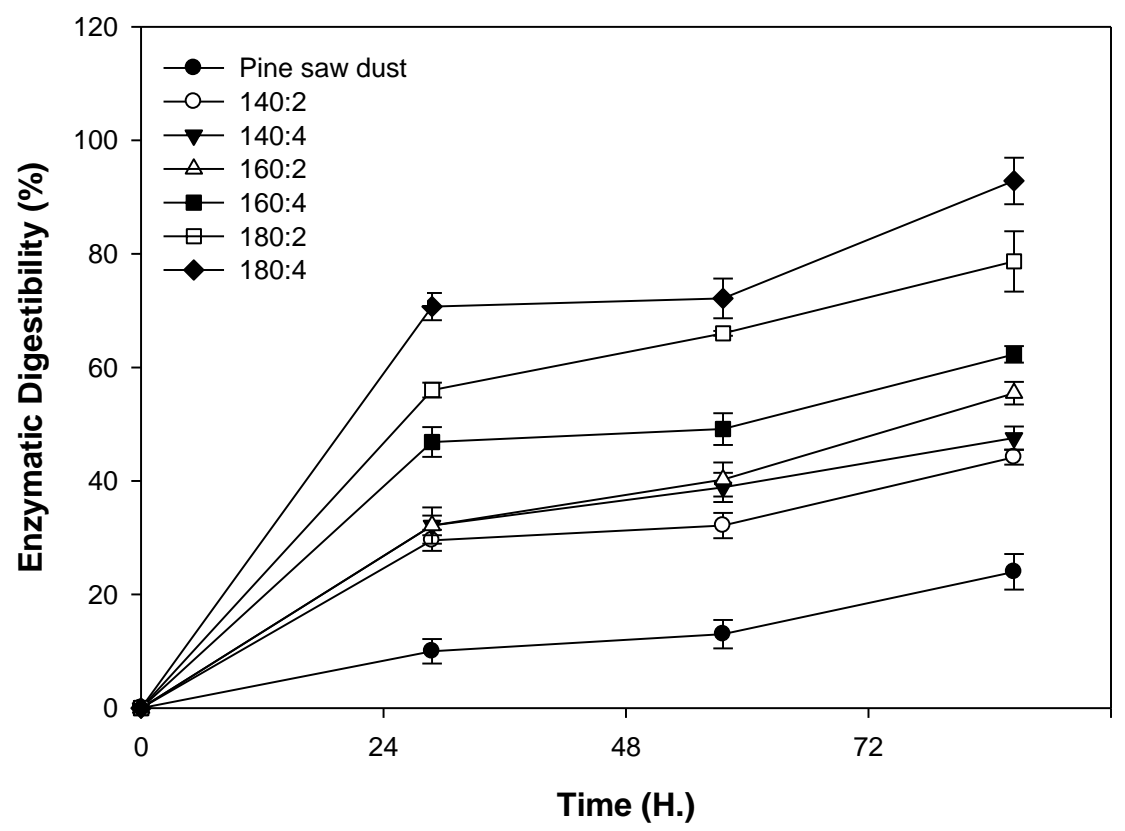

Figure 1. Digestibility and time graph.

Correlation of lignin yiled with enzymatic digestibility \& XRD

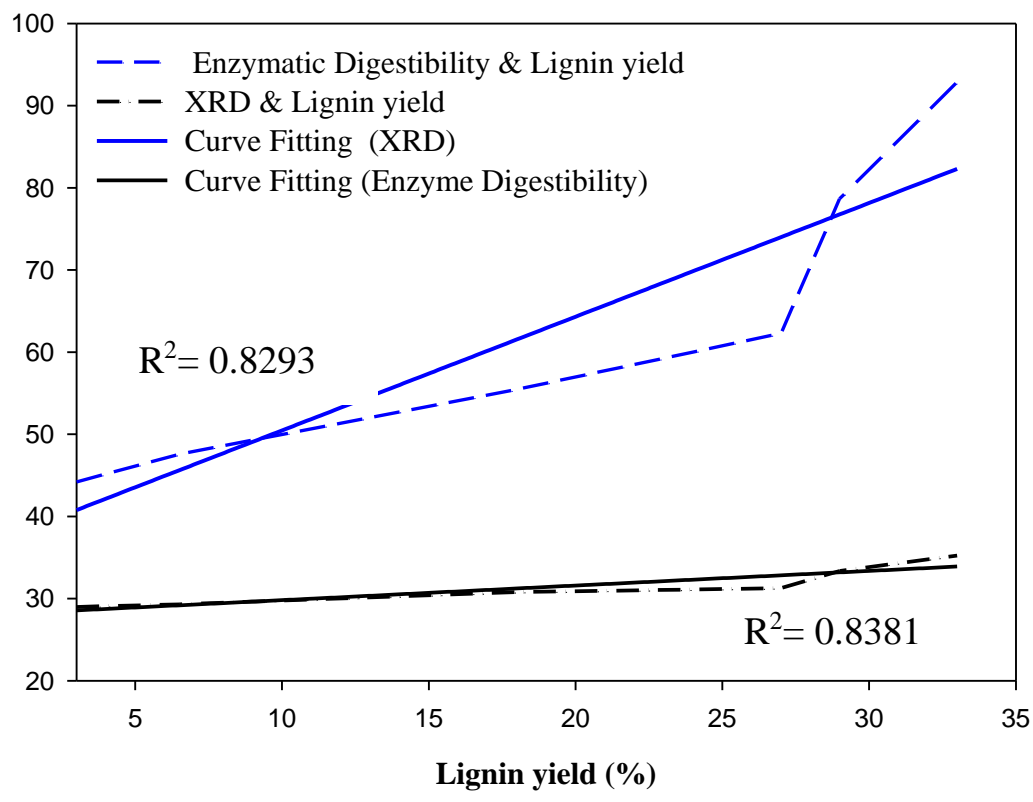

Figure 2. Correlation of enzymatic digestibility and XRD with lignin yield. 


\subsection{Gel Permeation Chromatography}

For the extracted lignin fractions, molecular weight analysis and chromatograms employing the GPC method were performed to more precisely understand their fragmentation during GVL fractionation. The results for this analysis are shown in Table 3, along with the weight average $\left(M_{w}\right)$ and number average $\left(M_{n}\right)$ molecular weights as well as the corresponding polydispersity $\left(M_{w} / M_{n}\right)$.

Table 3. Results of molecular weights and polydispersity.

\begin{tabular}{cccc}
\hline Sample & Mn & Mw & (Mw/Mn) P \\
\hline Pine MWL & 5157 & 10660 & 2.06 \\
\hline GVL Lignin 140:2 & 4164 & 12331 & 2.96 \\
\hline GVL Lignin 140:4 & 4942 & 11913 & 2.41 \\
\hline GVL Lignin 160:2 & 4575 & 13162 & 2.87 \\
\hline GVL Lignin 160:4 & 3897 & 10165 & 2.60 \\
\hline GVL Lignin 180:2 & 3279 & 7939 & 2.42 \\
\hline GVL Lignin 180:4 & 2847 & 7245 & 2.54 \\
\hline
\end{tabular}

As it is quite obvious in the table, the molecular weights ranged from 12,331 to $7245 \mathrm{gm} / \mathrm{mol}$, which is relatively high compared to a classical lignin, i.e., milled wood lignin (MWL). In one previous study where GVL was employed as a pretreatment reagent, lignin also exhibited heterogeneous and diverse properties due to the harsher process conditions [26]. From here, it is presumable that the lignin underwent condensation during this GVL treatment. In regards to polydispersity, as can be seen from the table, the value is in the range of 2.54-2.96 and is representative of a narrow margin, which shows a relative heterogeneity of lignin macromolecules. However, this high value of polydispersity shows that there are large amounts of low molecular weight species present from the isolated lignin fractions. This same phenomenon is also supported by the behavior of the chromatograms, which is illustrated in Figure 3.

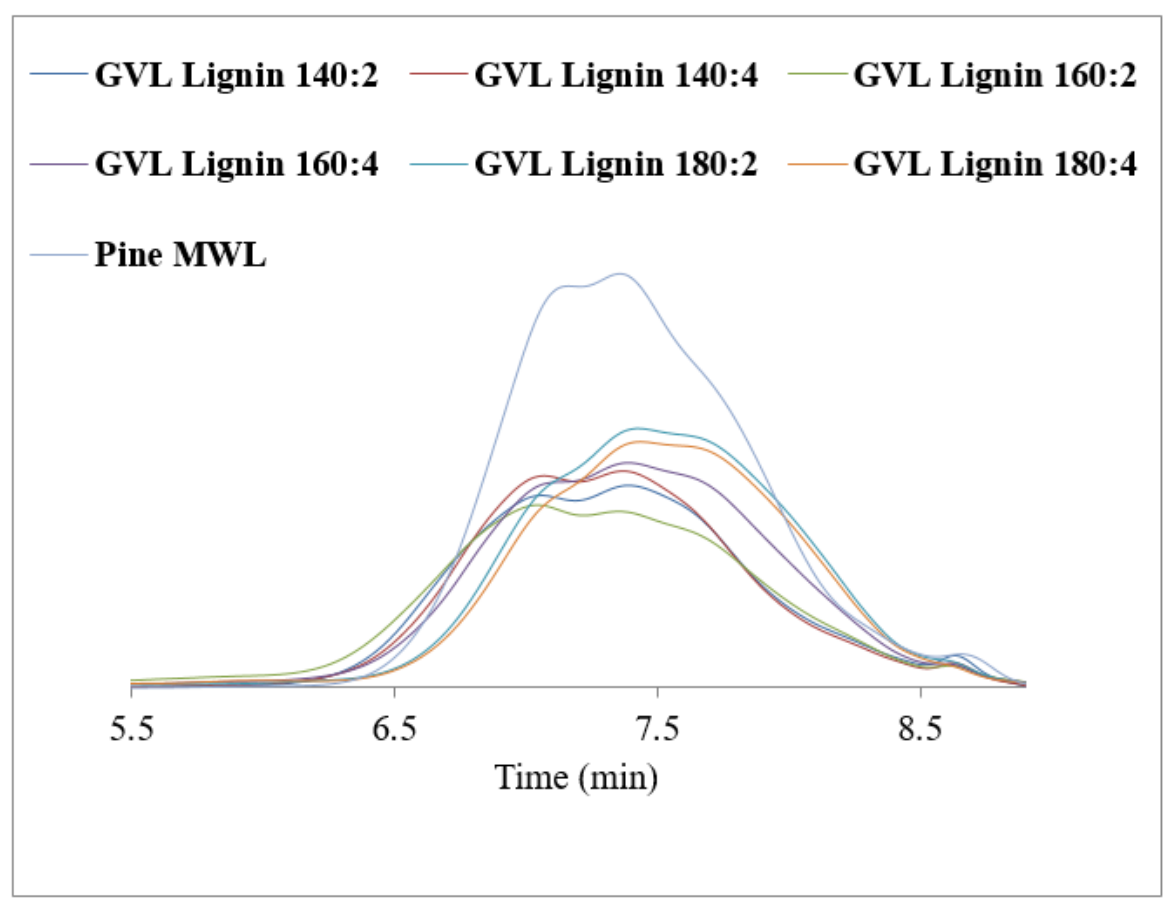

Figure 3. Gel permeation chromatography (GPC) chromatograms. 


\subsection{DFRC}

For the sake of structural investigation of the obtained lignins, the DFRC method was applied via its typical selective $\beta$-aryl ether structural degradation. The fractions were studied by GC-MS, and the results are shown in Table 4. As can be seen in the table values, each lignin fraction represents only the $\mathrm{G}$ type of units due to the typical natural G-unit composition of pinewood biomass. The values for DFRC results range from 300 to $150 \mu \mathrm{mol} / \mathrm{gm}$ of lignin for GVL treatment conditions, whereas the value of 810 represents an MWL value for very high G-units. It is obvious from the table that as the treatment severity increases, there is a clear, meaningful, decreasing trend in the DFCR values, showing that the thermal conditions have led to the degradation of the lignin molecules. From here, it can be suggested that the isolated lignin fractions, however, were scant in comparison to MWL but were lower in their $\beta$-aryl ether units.

Table 4. Derivatization followed by reductive cleavage (DFRC)—GC/MS results.

\begin{tabular}{cccc}
\hline Sample & G Units & S Units & Total \\
\hline Pine MWL & $810.6 \pm 34.9$ & - & $810.6 \pm 34.9$ \\
\hline GVL Lignin 140:2 & $300 \pm 35.8$ & - & $300 \pm 35.8$ \\
\hline GVL Lignin 140:4 & $250 \pm 36.8$ & - & $250 \pm 36.8$ \\
\hline GVL Lignin 160:2 & $242 \pm 46.0$ & - & $242 \pm 46.0$ \\
\hline GVL Lignin 160:4 & $210 \pm 10.4$ & - & $242 \pm 10.4$ \\
\hline GVL Lignin 180:2 & $196 \pm 24.7$ & - & $196 \pm 24.7$ \\
\hline GVL Lignin 180:4 & $150 \pm 48.1$ & - & $150 \pm 48.1$ \\
\hline
\end{tabular}

\section{7. $2 D-H S Q C-N M R$ Spectra}

For 2D-HSQC-NMR, the lignin samples were prepared using $20 \mathrm{mg}$ of lignin dissolved in $0.75 \mathrm{~mL}$ DMSO-D6, and then the analysis data were acquired with a Bruker AVANCE 600 spectrometer (Bruker, Germany). Meanwhile, the relative quantification and the corresponding assignments of $A_{\alpha}, B_{\alpha}$ and $\mathrm{C}_{\alpha}$ are tabulated in Table 5, and their corresponding NMR spectra are delineated and shown in Figure 4. It is quite obvious that the GVL extracted lignin, in comparison with MWL, was slightly lower in $\beta-\mathrm{O}-4$ contents, ranging from $23.8 \%$ at more severe conditions to $31.1 \%$ at rather mild conditions. However, the other linkages of $\beta-\beta$ and $\beta-5$ showed somewhat comparable values with MWL. In one previous study, $58.2 \%$ of $\beta-\mathrm{O}-4$ linkages were reported when they extracted lignin from cotton stalks with $80 \%$ aqueous $\mathrm{GVL}$ but at $170{ }^{\circ} \mathrm{C}$ and employing $\mathrm{H}_{2} \mathrm{SO}_{4}$ as a catalyst [29]. Our lower values might be due to the crude form of the extracted lignin fractions.

Table 5. Quantification (\%) of various structures in four selected lignin samples.

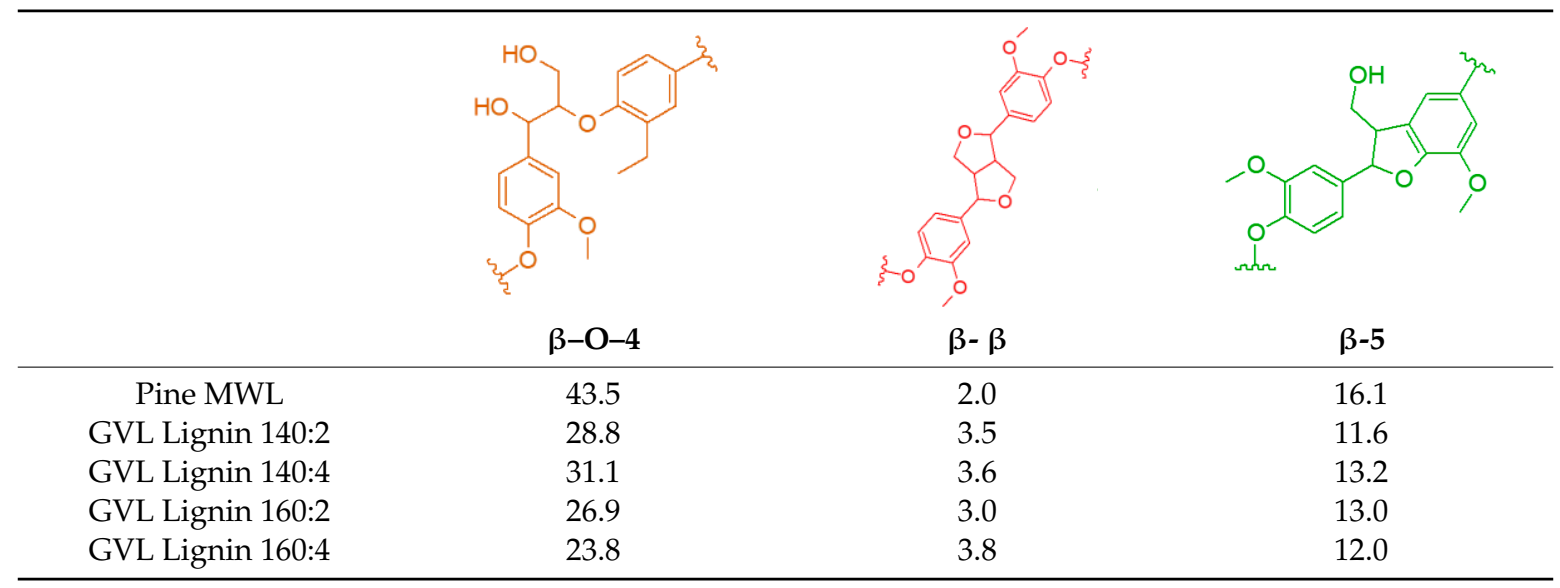



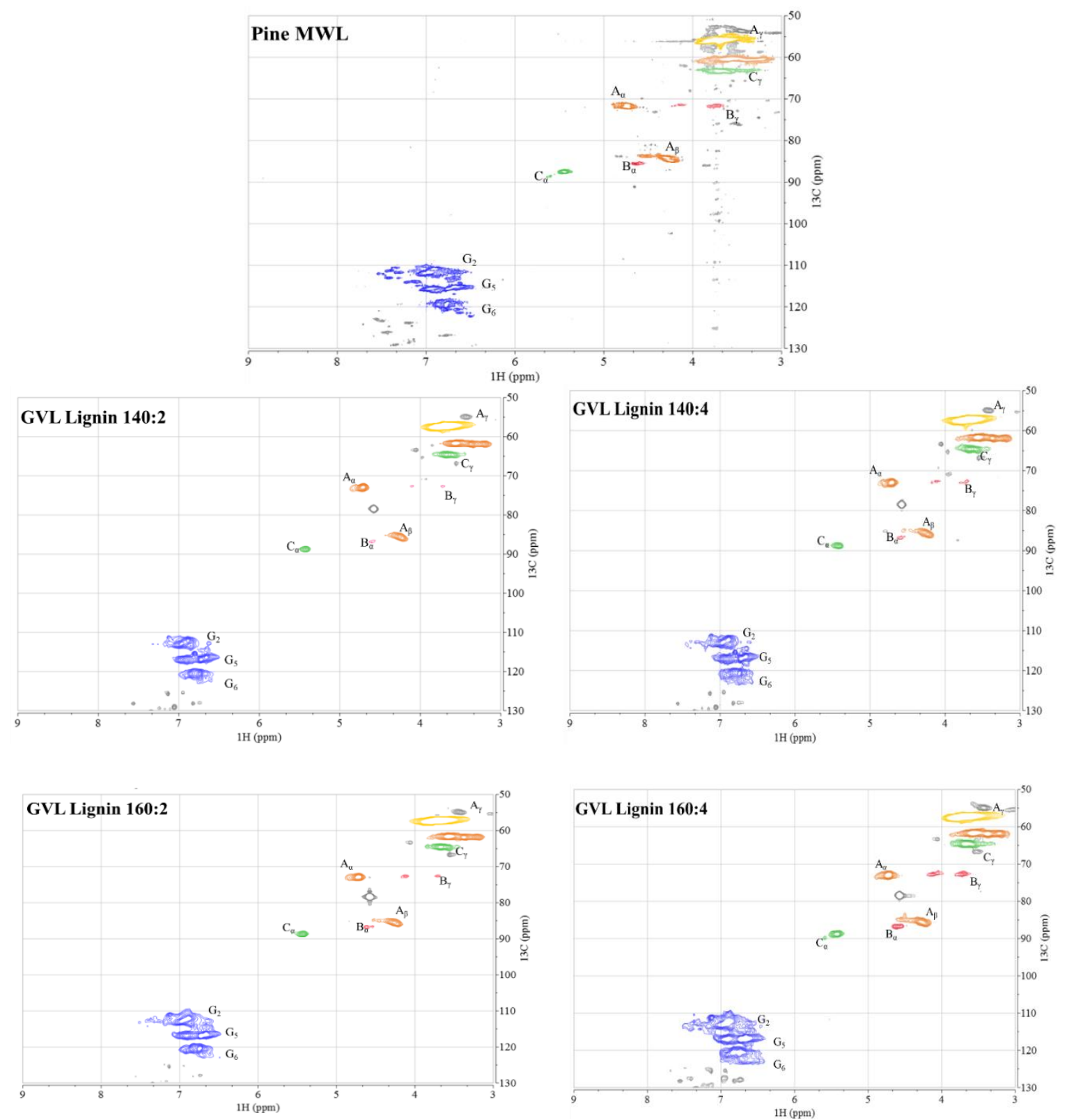

Figure 4. 2D-HSQC-NMR results for milled wood lignin (MWL) and four selected samples (140:2, 140:4, 160:2 and 160:4).

\section{Conclusions}

Gamma-valerolactone was found to be an efficient green reagent to deconstruct the native structure of milled pinewood biomass. This reagent, with only $80 \%$ aqueous concentration, together with the synergetic effect of heat, caused considerable compositional changes along with the high dissolution of lignin contents-up to $33 \%$ - and drastically enhanced the enzymatic digestibility of the corresponding polysaccharide fractions by $92 \%$. This fractionation approach, as a green and sustainable alternative, seems to be a potential addition to already adapted organosolv pretreatment strategies for lignocellulosic biomass. Thus, it can be suggested as one potential non-toxic option for the lignocellulosic biorefining processes.

Author Contributions: Conceptualization, A.A.R.; Data curation, M.A.A.; Formal analysis, J.H.L.; Investigation, M.A.A.; Supervision, J.W.C. All authors have read and agreed to the published version of the manuscript.

Funding: This research was funded by the Basic Science Research Program (NRF-2019R1A2C2086328) and the Technology Development Program to Solve Climate Changes (2017M1A2A2087627) of the National Research Foundation funded by the Ministry of Science and ICT. 
Conflicts of Interest: The authors declare no conflict of interest.

\section{References}

1. Ubando, A.T.; Felix, C.B.; Chen, W. Biorefineries in circular bioeconomy: A comprehensive review. Bioresour. Technol. 2019, 122585. [CrossRef] [PubMed]

2. Venkata Mohan, S.; Dahiya, S.; Amulya, K.; Katakojwala, R.; Vanitha, T.K. Can circular bioeconomy be fueled by waste biorefineries-A closer look. Bioresour. Technol. Rep. 2019, 7, 100277. [CrossRef]

3. Araújo, D.; Vilarinho, M.; Machado, A. Effect of combined dilute-alkaline and green pretreatments on corncob fractionation: Pretreated biomass characterization and regenerated cellulose film production. Ind. Crop. Prod. 2019, 141. [CrossRef]

4. Jin, J.; Yu, B.; Shi, Z.; Wang, C.; Chong, C. Lignin-based electrospun carbon nanofibrous webs as free-standing and binder-free electrodes for sodium ion batteries. J. Power Sources 2014, 272, 800-807. [CrossRef]

5. Khoshnevisan, B.; Shafiei, M.; Rajaeifar, M.A.; Tabatabaei, M. Biogas and bioethanol production from pinewood pre-treated with steam explosion and N-methylmorpholine-N-oxide (NMMO): A comparative life cycle assessment approach. Energy 2016, 114, 935-950. [CrossRef]

6. Kumar, B.; Bhardwaj, N.; Agrawal, K.; Chaturvedi, V.; Verma, P. Current perspective on pretreatment technologies using lignocellulosic biomass: An emerging biorefinery concept. Fuel Process. Technol. 2020, 199. [CrossRef]

7. Tian, S.Q.; Zhao, R.Y.; Chen, Z.C. Review of the pretreatment and bioconversion of lignocellulosic biomass from wheat straw materials. Renew. Sustain. Energy Rev. 2018, 91, 483-489. [CrossRef]

8. Jafari, Y.; Amiri, H.; Karimi, K. Acetone pretreatment for improvement of acetone, butanol, and ethanol production from sweet sorghum bagasse. Appl. Energy 2016, 168, 216-225. [CrossRef]

9. Stücker, A.; Schütt, F.; Saake, B.; Lehnen, R. Lignins from enzymatic hydrolysis and alkaline extraction of steam refined poplar wood: Utilization in lignin-phenol-formaldehyde resins. Ind. Crop. Prod. 2016, 85, 300-308. [CrossRef]

10. Kumari, D.; Singh, R. Pretreatment of lignocellulosic wastes for biofuel production: A critical review. Renew. Sustain. Energy Rev. 2018, 90, 877-891. [CrossRef]

11. Hassan, S.S.; Williams, G.A.; Jaiswal, A.K. Moving towards the second generation of lignocellulosic biorefineries in the EU: Drivers, challenges, and opportunities. Renew. Sustain. Energy Rev. 2019, 101, 590-599. [CrossRef]

12. Solarte-Toro, J.C.; Romero-García, J.M.; Martínez-Patiño, J.C.; Ruiz-Ramos, E.; Castro-Galiano, E.; CardonaAlzate, C.A. Acid pretreatment of lignocellulosic biomass for energy vectors production: A review focused on operational conditions and techno-economic assessment for bioethanol production. Renew. Sustain. Energy Rev. 2019, 107, 587-601. [CrossRef]

13. Sorn, V.; Chang, K.L.; Phitsuwan, P.; Ratanakhanokchai, K.; Dong, C.D. Effect of microwave-assisted ionic liquid/acidic ionic liquid pretreatment on the morphology, structure, and enhanced delignification of rice straw. Bioresour. Technol. 2019, 293, 121929. [CrossRef] [PubMed]

14. Zabed, H.M.; Akter, S.; Yun, J.; Zhang, G.; Awad, F.N.; Qi, X.; Sahu, J.N. Recent advances in biological pretreatment of microalgae and lignocellulosic biomass for biofuel production. Renew. Sustain. Energy Rev. 2019, 105, 105-128. [CrossRef]

15. Cebreiros, F.; Clavijo, L.; Boix, E.; Ferrari, M.D.; Lareo, C. Integrated valorization of eucalyptus sawdust within a biorefinery approach by autohydrolysis and organosolv pretreatments. Renew Energy 2020, 149, 115-127. [CrossRef]

16. Ramakoti, B.; Dhanagopal, H.; Deepa, K.; Rajesh, M.; Ramaswamy, S.; Tamilarasan, K. Solvent fractionation of organosolv lignin to improve lignin homogeneity: Structural characterization. Bioresour. Technol. Rep. 2019, 7, 100293. [CrossRef]

17. Tan, X.; Zhang, Q.; Wang, W.; Zhuang, X.; Deng, Y.; Yuan, Z. Comparison study of organosolv pretreatment on hybrid pennisetum for enzymatic saccharification and lignin isolation. Fuel 2019, 249, 334-340. [CrossRef]

18. Ye, L.; Han, Y.; Feng, J.; Lu, X. A review about GVL production from lignocellulose: Focusing on the full components utilization. Ind. Crop. Prod. 2020, 144, 112031. [CrossRef]

19. Sun, S.N.; Chen, X.; Tao, Y.H.; Cao, X.F.; Li, M.F.; Wen, J.L.; Nie, S.X.; Sun, R.C. Pretreatment of Eucalyptus urophylla in $\gamma$-valerolactone/dilute acid system for removal of non-cellulosic components and acceleration of enzymatic hydrolysis. Ind. Crop. Prod. 2019, 132, 21-28. [CrossRef] 
20. Jia, L.; Qin, Y.; Wen, P.; Zhang, T.; Zhang, J. Alkaline post-incubation improves cellulose hydrolysis after $\Gamma$-valerolactone/water pretreatment. Bioresour. Technol. 2019, 278, 440-443. [CrossRef]

21. Jin, L.; Yu, X.; Peng, C.; Guo, Y.; Zhang, L.; Xu, Q.; Zhao, Z.K.; Liu, Y.; Xie, H. Fast dissolution pretreatment of the corn stover in gamma-valerolactone promoted by ionic liquids: Selective delignification and enhanced enzymatic saccharification. Bioresour. Technol. 2018, 270, 537-544. [CrossRef] [PubMed]

22. Li, X.; Liu, Q.; Si, C.; Lu, L.; Luo, C.; Gu, X.; Liu, W.; Lu, X. Green and efficient production of furfural from corn cob over H-ZSM-5 using $\gamma$-valerolactone as solvent. Ind. Crop. Prod. 2018, 120, 343-350. [CrossRef]

23. Ahmed, M.A.; Rehman, M.S.U.; Terán-Hilares, R.; Khalid, S.; Han, J.I. Optimization of twin gear-based pretreatment of rice straw for bioethanol production. Energy Convers. Manag. 2017, 141, 120-125. [CrossRef]

24. Sluiter, J.B.; Ruiz, R.O.; Scarlata, C.J.; Sluiter, A.D.; Templeton, D.W. Compositional analysis of lignocellulosic feedstocks. 1. Review and description of methods. J. Agric. Food Chem. 2010, 58, 9043-9053. [CrossRef] [PubMed]

25. Kim, J.Y.; Park, S.Y.; Lee, J.H.; Choi, I.G.; Choi, J.W. Sequential solvent fractionation of lignin for selective production of monoaromatics by Ru catalyzed ethanolysis. RSC Adv. 2017, 7, 53117-53125. [CrossRef]

26. Angelini, S.; Ingles, D.; Gelosia, M.; Cerruti, P.; Pompili, E.; Scarinzi, G.; Cavalaglio, G.; Cotana, F.; Malinconico, M. One-pot lignin extraction and modification in $\gamma$-valerolactone from steam explosion pre-treated lignocellulosic biomass. J. Clean. Prod. 2017, 151, 152-162. [CrossRef]

27. Jung, Y.H.; Kim, H.K.; Park, H.M.; Park, Y.C.; Park, K.; Seo, J.H.; Kim, K.H. Mimicking the Fenton reaction-induced wood decay by fungi for pretreatment of lignocellulose. Bioresour. Technol. 2015, 179, 467-472. [CrossRef]

28. Ko, J.K.; Bak, J.S.; Jung, M.W.; Lee, H.J.; Choi, I.G.; Kim, T.H.; Kim, K.H. Ethanol production from rice straw using optimized aqueous-ammonia soaking pretreatment and simultaneous saccharification and fermentation processes. Bioresour. Technol. 2009, 100, 4374-4380. [CrossRef]

29. Wu, M.; Liu, J.K.; Yan, Z.Y.; Wang, B.; Zhang, X.M.; Xu, F.; Sun, R.-C. Efficient recovery and structural characterization of lignin from cotton stalk based on a biorefinery process using a $\gamma$-valerolactone/water system. RSC Adv. 2016, 6, 6196-6204. [CrossRef]

(C) 2020 by the authors. Licensee MDPI, Basel, Switzerland. This article is an open access article distributed under the terms and conditions of the Creative Commons Attribution (CC BY) license (http://creativecommons.org/licenses/by/4.0/). 